\title{
Finite Element Analysis of the Temperature Field of an Emergency Brake and Study of its Thermal Properties
}

\author{
H. Wen, F. Yang, W. Q. Lv, Y. X. Chen, and Q. W. Wang ${ }^{1}$ \\ School of Mechanical Engineering, Taiyuan University of Science and Technology, Taiyuan, China \\ 1 noveldavid@126.com
}

\begin{abstract}
FFor simulation of typical operating conditions of an emergency brake, analyze the theoretical heat energy of single emergency braking. The formula of the maximum temperature of a contact point was derived from the theory of friction heat conduction during braking. The finite element model of the disc brake temperature field was constructed with ANSYS/LS-DYNA software. The effect of brake safety factor and different thermal properties on the temperature field is analyzed, indicating that the temperature distribution of ductile iron brake friction pairs is superior to the steel brake ones. The results and analysis provide certain indications of the design and applicability of an emergency brake.
\end{abstract}

Keywords: disc brake, temperature field, theory of heat conduction, finite element, thermal properties.

Introduction. Lifting machinery provides displacement of objects through the coordinated motion of various operating mechanisms to complete handling operation, which has the characteristics of intermittent operation, load variation, and frequent braking. From the safety viewpoint, lifting machinery is characterized by high energy accumulation and high hazard and thus falls into a category of special equipment, redulated by the respective norms ans standards, which are described elsewhere [1]. An adequate operating of hoisting machinery strongly depends on braking performance and reliability of the braking system, especially under conditions of lifting molten metals and other dangerous objects.

In principle, the emergency braking device of a hoisting mechanism should be installed at the end of the low-speed shaft equipment, which is usually represented by a caliper disc brake. The mechanical energy of the system in opersation is converted to heat by the friction between brake disc and the friction lining, which is absorbed by the friction pair [2]. A caliper disc brake combines the energy converter and heat exchanger, which design and structure should conform to the heat transfer theory and be based on the thermal analysis. Thus, the analysis of friction pair surface temperature field and the material properties is instrumental for ensuring the brake applicability and reliability and may provide a theoretical justification of the braking system design and of the optimal friction pair choice.

\section{Emergency Brake Friction Thermal Analysis.}

1.1. Theoretical Calculations of the Brake Energy for Typical Braking Conditions. During operation of the hoisting mechanism, e.g. when lifting the molten metal and other dangerous products, the emergency brake should ensure the system security against possible cases of blackout/loss of power supply or excessive motion speed, which are the typical operating conditions for an emergency brake. In the absence of electric braking [3], all the mechanical energy of the system will be sustained only by the emergency brake and be almost completely converted to friction heat in a very short time period (generally, no more than $3 \mathrm{~s}$ ).

Assume that the braking torque is constant during a single act of braking by the emergency brake, which is based on the spring brake principle. The total heat $Q$ (in $\mathrm{J}$ ) generated in the brake friction pair after one emergency braking is calculated as follows: 


$$
Q=(\pi / 60) n_{1} M_{z h} t_{z h},
$$

where $n_{1}$ is the initial speed of brake axle before braking (in rpm), normally $n_{1}=1.15 n_{N}$, $t_{z h}$ is the time of theoretical braking (in s), $M_{z h}$ is the braking torque (in N.m),

$$
M_{z h}=K_{Z} \frac{P_{Q G L} D_{0}}{2 m} \eta_{z}^{\prime} \eta_{d} \eta_{t}
$$

where $K_{Z}$ is the braking safety factor of a low-speed shaft, which ranges from 1.5 to 2.5 , $P_{Q G L}$ is the gross load (in N), $D_{0}$ is coiling block winding diameter (in $\mathrm{m}$ ), $m$ is the lifting pulley block ratio, and $\eta_{z}^{\prime}, \eta_{d}$, and $\eta_{t}$ are the efficiencies of the pulley block, leading sheave and coiling block, respectively.

1.2. Heat Conduction Theory of Braking Friction. Due to the above features of short-term emergency braking, a high temperature occurs at the friction pair surfaces, which will result in the heat fading of the friction performance. When the heat fading rate reaches its critical value, the braking system will get out of control, which may lead to malfunction and accidents.

The temperature distribution in a friction pair is related to the braking time, braking frequency and the heat dissipation from the free surface into the environment during braking. In case where the friction pair materials are isotropic, the heat conduction during braking will be controlled by the following differential equation [4-8]:

$$
\nabla^{2} T_{i}=\frac{1}{\alpha_{\iota}} \frac{\partial T_{i}}{\partial t} \quad(i=1,2)
$$

The boundary conditions for the above formula are as follows:

(i) the total heat generated by friction (contact point) is equal to the sum of endothermic object 1 and object 2, namely: $\lambda_{1} \frac{\partial T_{1}}{\partial n}-\lambda_{2} \frac{\partial T_{2}}{\partial n}=q(x, y, 0, t)$;

(ii) the temperature in the true contact point of the friction pair is the same: $T_{1}(x, y, 0, t)=T_{2}(x, y, 0, t)$;

(iii) the heat interchange between brake surface and environment conforms to the Newton law of cooling: $-\lambda_{i} \frac{\partial T_{i}}{\partial n}=\sigma_{i}^{\prime}\left(T_{i}-T_{f}\right)$;

(iv) the initial condition is: $t=0, T_{1}=T_{2}=20^{\circ} \mathrm{C}$ (the average ambient temperature).

Here $\nabla^{2} T$ is the Laplace operator of temperature $T$, which can be expressed as $T(x, y, z, t), \alpha$ is thermal diffusivity (in $\mathrm{m}^{2} / \mathrm{s}$ ), $\alpha=\lambda /(\rho c), \rho$ is material density (in $\left.\mathrm{kg} / \mathrm{m}^{3}\right), \quad c$ is specific heat [in $\left.\mathrm{J} /\left(\mathrm{kg} \cdot{ }^{\circ} \mathrm{C}\right)\right], \lambda$ is thermal conductivity [in $\mathrm{W} /\left(\mathrm{m} \cdot{ }^{\circ} \mathrm{C}\right)$ ], $q(x, y, 0, t)$ is friction surface heat generation rate at time instant $t, \sigma$ is body surface convection coefficient $\left[\mathrm{in} \mathrm{W} /\left(\mathrm{m}^{2} \cdot{ }^{\circ} \mathrm{C}\right)\right]$, and $T_{f}$ is environment temperature.

1.3. Theoretical Calculation of the Maximum Temperature during Braking. The asymmetrical contact between friction surfaces leads to the unknown distribution and variation of the true contact points during braking, resulting in the nonuniformity of their temperature fields [9-11]. The maximum temperature at a certain contact point can be calculated by the following formula:

$$
T_{\max }=T^{*}+T_{c}
$$

where $T^{*}$ is the average temperature of the friction surface and $T_{c}$ is the flash point temperature. 
In the process of braking, the measured temperature is different at different locations of the nominal friction surface, varying within a certain range. The experimental temperature evolutions distibutions are depicted in Fig. 1 by curves $1-4$ curves, where evolution of the average temperature $T^{*}$ is illustrated by the mean curve 5 .

The flash point temperature can be calculated by the model [2, 12], which is schematically presented in Fig. 2. Assume that the average diameter of a contact point is $d_{r}$. When the microscopic bulge of pair 1 moves along a smooth plane 2, the distance between the beginning of the contact and the bulge softening point is $L_{r}$.

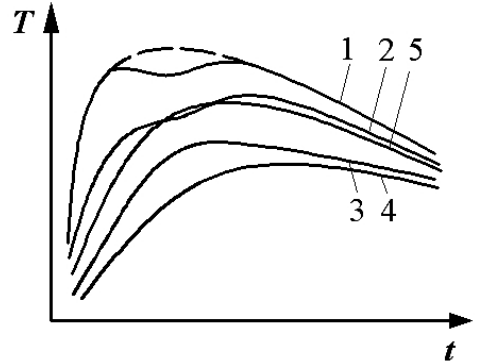

Fig. 1. The average temperature $T^{*}$. Fig. 2. The calculation model of flash point temperature.

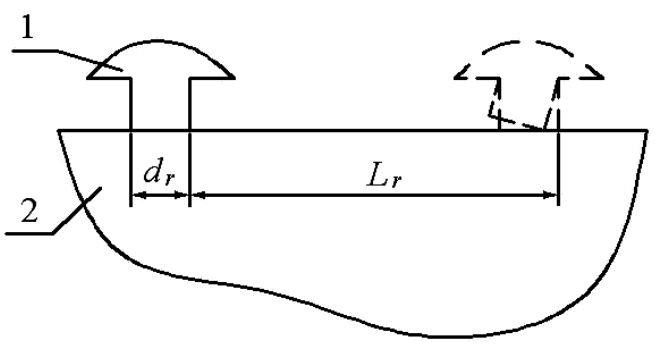

The calculation formula of a single contact point temperature complies with the above differential equation of heat conduction (3), which can be reduced for friction pair 1 to the following form:

$$
\left\{\begin{array}{l}
\frac{\partial^{2} T_{1}}{\partial z^{2}}=\frac{1}{\alpha_{1}} \frac{\partial T_{1}}{\partial t}, \\
\left.\lambda_{1} \frac{\partial T_{1}}{\partial z}\right|_{z=0}=-q_{1} .
\end{array}\right.
$$

The solution of Eq. (5) is

$$
T_{1}=\frac{q_{1}}{\sqrt{\lambda_{1} \rho_{1} c_{1}}}\left[\frac{2 \sqrt{t}}{\sqrt{\pi}} \exp \left(-\frac{z^{2}}{4 \alpha_{1} t}\right)-\frac{z}{\sqrt{\alpha_{1}}} E_{r} f_{c} \frac{z}{2 \sqrt{\alpha_{1} t}}\right] .
$$

For $z=0$, the surface temperature of pair 1 can be derived from Eq. (6) as follows

$$
T_{1}(0, t)=2 q_{1} \sqrt{t} / \sqrt{\pi \rho_{1} c_{1} \lambda_{1}} \quad\left(0 \leq t \leq L_{r} / v_{0}\right) .
$$

It follows form Eq. (7) that, under certain boundary conditions, the maximum temperature of a certain microscopic bulge, which has been shifted at the sliding distance $L_{r}$, is

$$
T_{1 \max }=2 q_{1} \sqrt{L_{r} / v_{0}} / \sqrt{\pi \rho_{1} c_{1} \lambda_{1}} \text {. }
$$

If $q_{2}=a_{T n}$, then $q_{1}=\left(1-a_{T n}\right) q$, where $q$ is the total heat flux density in the true contact point. Assuming that there is no temperature fluctuation in the contact, heat distribution coefficient $a_{T n}$ can be determined via the average temperature, namely:

$$
\left\{\begin{array}{l}
a_{T n}=\sqrt{L_{r} \lambda_{2} \rho_{2} c_{2}} /\left(\sqrt{L_{r} \lambda_{2} \rho_{2} c_{2}}+\sqrt{d_{r} \lambda_{1} \rho_{1} c_{1}}\right), \\
1-a_{T n}=\sqrt{d_{r} \lambda_{1} \rho_{1} c_{1}} /\left(\sqrt{L_{r} \lambda_{2} \rho_{2} c_{2}}+\sqrt{d_{r} \lambda_{1} \rho_{1} c_{1}}\right) .
\end{array}\right.
$$


Thus,

$$
T_{1 \max }=\frac{2 q \sqrt{d_{r} L_{r}}}{\sqrt{\pi v_{0}}\left(\sqrt{L_{r} \lambda_{2} \rho_{2} c_{2}}+\sqrt{d_{r} \lambda_{1} \rho_{1} c_{1}}\right)} .
$$

Finally, the highest theoretical temperature of the microscopic bulge contact is

$$
T_{1 \text { max }}^{*}=\frac{2 q \sqrt{d_{r} L_{r}}}{\sqrt{\pi v_{0}}\left(\sqrt{L_{r} \lambda_{2} \rho_{2} c_{2}}+\sqrt{d_{r} \lambda_{1} \rho_{1} c_{1}}\right)}+T^{*},
$$

where $v_{0}$ is relative sliding velocity.

2. Finite Element Model of the Disc Brake Temperature Field.

2.1. Assumptions of the Finite Element Model. The temperature field finite element model is constructed using the following assumptions [13, 14]:

(i) all materials under study are isotropic;

(ii) the material parameters do not change with the temperature variation;

(iii) the kinetic energy during braking is completely converted into frictional heat;

(iv) frictional heat is generated in the pair contact surface during braking and is transferred to the brake disc and friction lining in the form of heat flux.

\subsection{Finite Element Model.}

2.2.1. Friction Pair Material Parameters. To analyze the impact of material properties on the temperature field of the friction pair, ductile iron and cast steel were selected as the brake disc materials, while copper-based material produced by the powder metallurgy technology was selected for the friction lining. The respective parameters $[15,16]$ are listed in Table 1.

$\mathrm{T}$ a b 1 e 1

Various Parameters of the Friction Pair

\begin{tabular}{|c|c|c|c|c|c|c||}
\hline Material & $\begin{array}{c}\text { Elastic } \\
\text { modulus } \\
(\mathrm{GPa})\end{array}$ & $\begin{array}{c}\text { Poisson's } \\
\text { ratio }\end{array}$ & $\begin{array}{c}\text { Density } \\
\left(\mathrm{kg} / \mathrm{m}^{3}\right)\end{array}$ & $\begin{array}{c}\text { Heat } \\
\text { conduction } \\
\text { rate } \\
\left(\mathrm{W} / \mathrm{m} \cdot{ }^{\circ} \mathrm{C}\right)\end{array}$ & $\begin{array}{c}\text { Special } \\
\text { heat } \\
\left(\mathrm{J} / \mathrm{kg} \cdot{ }^{\circ} \mathrm{C}\right)\end{array}$ & $\begin{array}{c}\text { Heat expansion } \\
\text { coefficient } \\
\left({ }^{\circ} \mathrm{C}^{-1}\right)\end{array}$ \\
\hline Ductile iron & 120 & 0.31 & 7900 & 75.0 & 450 & $1.1 \cdot 10^{-5}$ \\
\hline Cast steel & 211 & 0.31 & 7830 & 30.0 & 500 & $9.6 \cdot 10^{-5}$ \\
\hline Copper base & 3 & 0.30 & 4900 & 12.6 & 4900 & $1.62 \cdot 10^{-5}$ \\
\hline
\end{tabular}

2.2.2. Energy Conversion of Friction Pair and Braking Mechanism Parameters. The dependence between the friction brake total energy $Q$ of the friction pair and the design parameters of the braking mechanisms can be derived from Eqs. (1) and (2), as follows:

$$
Q=K_{Z} t_{z h} \frac{\pi n_{1} P_{Q G L} D_{0} \eta_{z}^{\prime} \eta_{d} \eta_{t}}{120 m}
$$

2.2.3. Finite Element Model of the Friction Pair. The finite element solid model of the brake friction pair, which is based on the principle of friction heat production, is shown in Fig. 3. The respective mesh consists of thee eight-node hexahedral solid elements using the ANSYS LS-DYNA software: the number of finite elements is 1696 for the brake disc and 160 for the friction lining. The transiently changing angular velocity of the brake disc and friction lining extrusion force are imposed by the time function. 


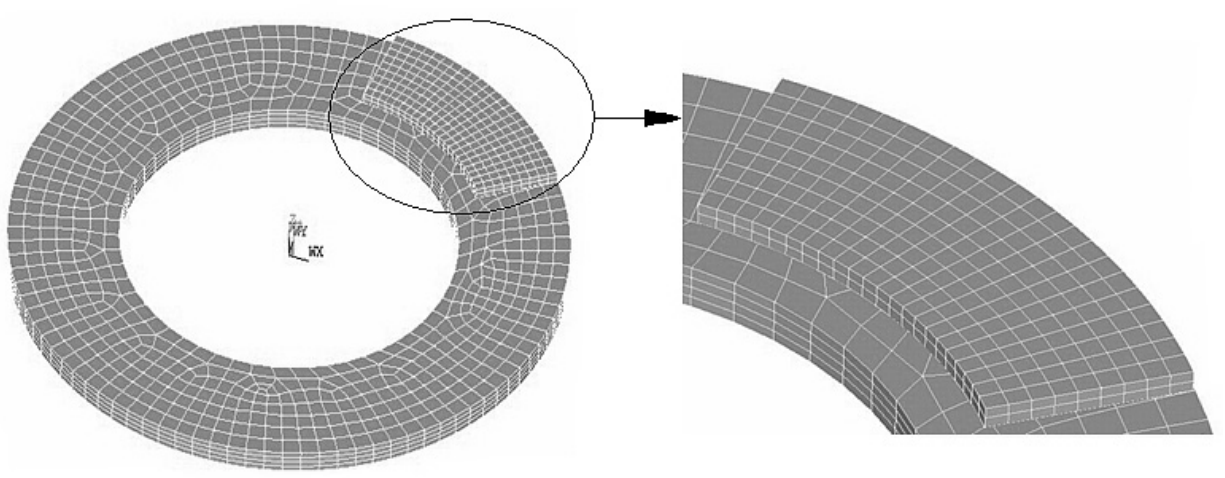

Fig. 3. Finite element model of friction pair.

\subsection{Calculation Results.}

2.3.1. Effect of the Brake Safety Factor on the Temperature Field. The derived Eq.(12) and the brake temperature calculation for a typical braking condition imply that the braking heat $Q$ is controlled only with the brake safety factor $K_{Z}$ and the braking time $t_{z h}$ under the premise of other parameters being constant. The braking heat distribution of friction pair is shown in Fig. 4 for the brake safety factor values of 1.5 and 2.5. The respective brake times is 3.5 and $2.1 \mathrm{~s}$. The braking energy simulation by the finite element method shows that the area with high temperature distribution increases with the brake safety factor $K_{Z}$. This can be explained as follows: a higher brake safety factor results in a shorter brake time, and, thus, the convection between the friction pair boundary and the external one will have less effect on the heat dissipation.

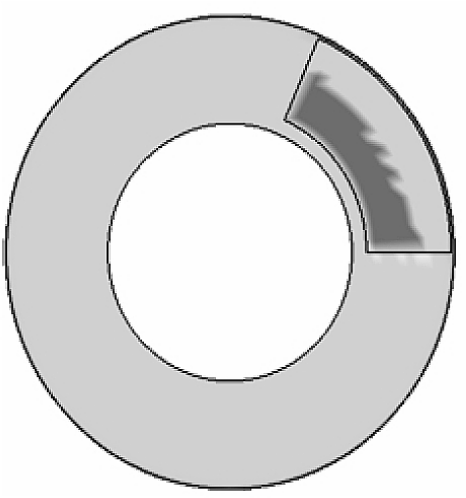

a

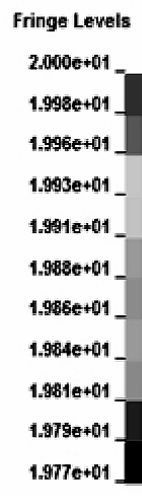

$1.977 e+01$

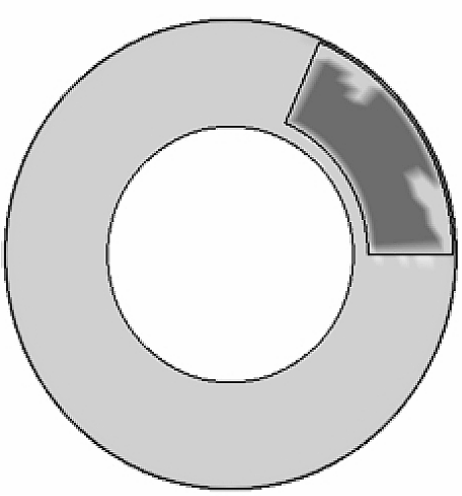

b

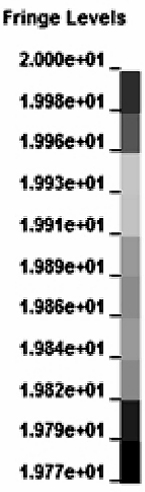

Fig. 4. The effect of the brake safety factor on the temperature field: the temperature distribution for $K_{Z}=1.5, t_{z h}=3.5 \mathrm{~s}$ (a) and $K_{Z}=2.5, t_{z h}=2.1 \mathrm{~s}$ (b).

2.3.2. Effect of Brake Disc Material Properties on the Temperature Field. Both ductile iron and cast steel brake discs are paired with the friction plate. At the same initial speed $n_{0}$, loads and material parameters, the friction brake temperature field was calculated by the finite element method and shown in Fig. 5 for the brake safety factor $K_{Z}=2$ and braking time $t_{z h}=0.5 \mathrm{~s}$. The surface temperature of the ductile iron brake disc is significantly lower than that of cast steel, as seen from Fig. 5. The physical properties of the two materials listed in the Table 1 indicate that the heat conduction rae in the ductile iron is higher than in the cast steel due to its higher density, smaller specific heat capacity and 1.5-times higher heat transfer coefficient, which enhances the rate of frictional heat 


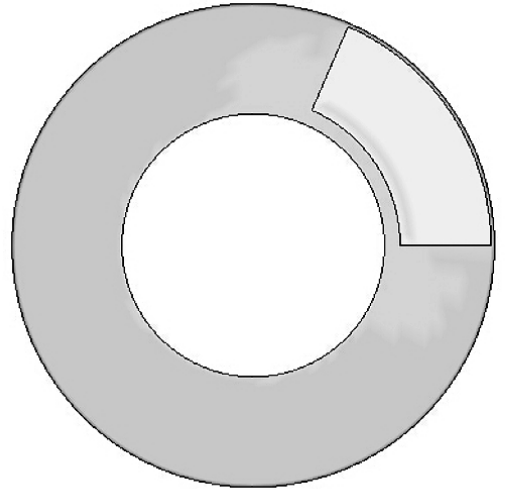

a

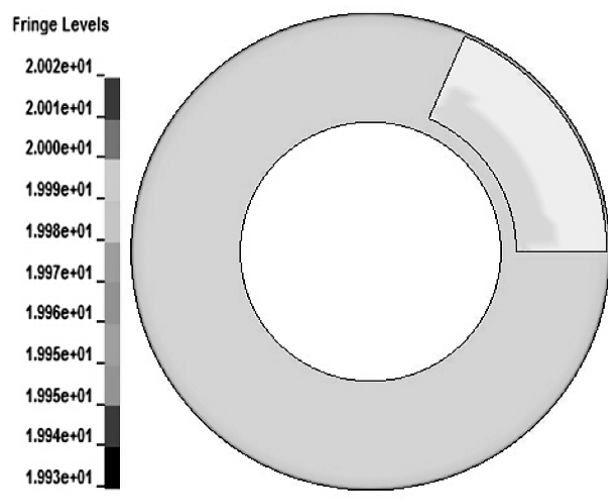

b
Fringe Levels

$2.001 e+01$

$2.001 e+01$

$2.000 \mathrm{e}+01$

$1.999 \mathrm{e}+01$

$1.998 \mathrm{e}+01$

$1.997 \mathrm{e}+01$.

$1.996 \mathrm{e}+01$ _

$1.995 \mathrm{e}+01$.

$1.994 \mathrm{e}+01$

$1.993 e+01$

$1.992 \mathrm{e}+01$

Fig. 5. The effect of the brake disc materials on the temperature field: the ductile iron brake disc (a); the cast steel brake disc (b).

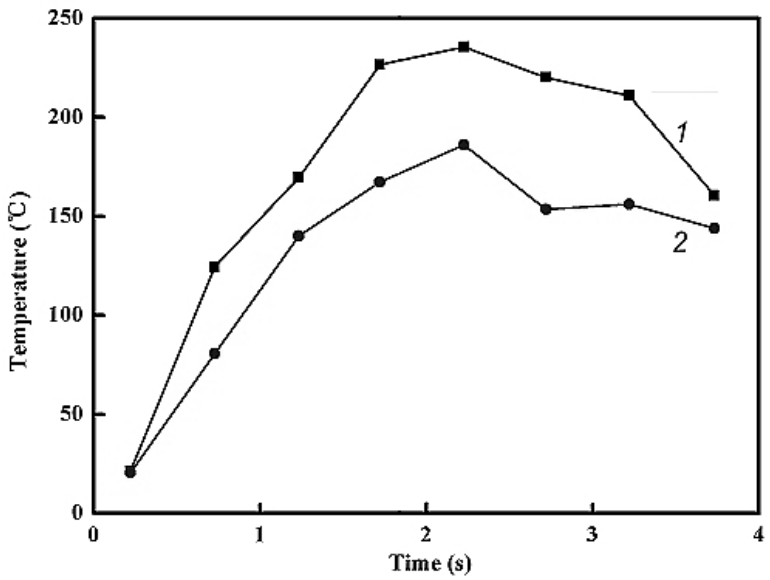

Fig. 6. The temperature-time curve of the cast steel (1) and ductile iron (2) discs.

transmission from the contact surface to the substrate, resulting in the significant reduction of the friction surface temperature. Moreover, the temperature predicted by the finite element analysis is consistent with the temperature-time curve of ductile iron and cast steel, as shown in Fig. 6.

In summary, the brake safety factor and the brake disc material properties have a significant impact on the brake temperature field.

\section{Conclusions}

1. Under conditions of equal initial speed and load, the high-temperature distribution in the friction pair is more concentrated when the brake safety factor is higher. A justified choice of the brake safety coefficient is very instrumental for the braking system design.

2. In order to achieve a higher brake safety factor or/and more concentrated high-temperature distribution along the brake friction pair surface, it is expedient to choose the brake disc materials with higher thermophysical properties, such as ductile iron, which have a better thermal effect on the temperature field than cast steel.

3. The temperature field simulation analysis of emergency brake via ANSYS LS-DYNA is instrumental for the safety braking system design. 
Acknowledgments. This work is supported by the Shanxi Province Excellent Innovation Project for Graduate (Grant No. 20123102), Shanxi Province Natural Science Foundation (Grant No. 2010011031-4), Development and Demonstration of Logistics Prodigy Construction and Operation Technology of the Western Port (2011-328-222-560).

1. H. Wen and Y. X. Qin, Lifting Appliance [in Chinese], China Machine Press, Beijing (2013).

2. T. Wang and W. J. Zhu, Friction Brake [in Chinese], South China University of Technology Press, Guangzhou (1992).

3. Y. Shiao, Q. A. Nguyen, and G. D. Huang, "Design and validation of outer rotor magnetorheological brake with multiple poles," Mater. Res. Innov., 18, Issue S3, S16-S21 (2014).

4. J. H. Choi and I. Lee, "Finite element analysis of transient thermoelastic behaviors in disk brakes," Wear, 257, 47-58 (2004).

5. A .Yevtushenko and E. Ivanyk, "Determination of temperature for sliding contact with application for braking systems," Wear, 206, 53-59 (1997).

6. J. Taler and P. Oclon, "Finite element method in steady-state and transient heat conduction," in: R. B. Hetnarski, Encyclopedia of Thermal Stresses, Springer (2014), pp. 1604-1633.

7. L. Hua and S. S. Xiang, "Study on the transient thermal field of the air disc brake of vehicle," Lubricat. Eng., 32, No. 5, 8-11 (2007).

8. L. Rudolf, Analysis and Design of Automotive Brake System, China Machine Press, Beijing (1985).

9. Y. Wang, X. K. Cao, and A. Y. Yao, "Study on the temperature field of disc brake friction flake," J. Wuhan Univ. Technol., 23, No. 7, 22-24 (2001).

10. G. F. Lu and S. Y. Guo, "Numerical simulation of transient temperature field of disc-pad brake," Mech. Res. Appl., 19, No. 1, 31-32 (2006).

11. X. M. Chen, H. Wen, Q. W. Wang, et al., "The research of industrial brake temperature measurement based on nano-materials and nano-technology," Key Eng. Mater., 609-610, 1254-1259 (2012).

12. B. J. Ma, L. L. Han, and J. Zhu, "The temperature field analysis of disc brake," J. Xi'an Inst. Technol., 18, No. 4, 311-315 (1998).

13. L. Li, J. Song, and Y. Li, "Study on fast finite element simulation model of thermal analysis of vehicle brake," J. Syst. Simul., 17, No. 12, 2869-2872 (2005).

14. M. Naji, M. Al-Nimr, and S. Masoud, "Transient thermal behavior of a cylindrical brake system," Heat Mass Transfer., 36, 45-49 (2000).

15. H. X. Gao, J. X. Liu, and R. J. Zhu, "Study on friction wear property of train brake materials by copper-based powder metallurgy," J. Mater. Sci. Eng., 23, 871-874 (2005).

16. M. J. Lu, Practical Mechanical Engineering Materials Handbook [in Chinese], Liaoning Science and Technology Press, Liaoning (2004). 